\title{
Integrative Stem: Design and Implementation of an 8th grade Technology Curriculum (Research to Practice)
}

\section{Mr. Norman "Storm" Robinson III, Georgia Institute of Technology}

Norman "Storm" Robinson, III is an award winning educator, curriculum designer, presenter, professional development trainer and instructional coach. He has offered programs that have inspired teachers and students to increase interest and participation in STEM/STEAM courses and concepts. His energy, content knowledge and instructional strategies are supported by research and delivered in a style that is relatable and receptive and impacts teaching and learning.

Storm began his career as a Mathematics Teacher at Tanglewood Middle School in Greenville, South Carolina. He was awarded Teacher of the Year after his second year in the classroom. Also at this time he was selected to serve on the Curriculum Leadership Institute for the Greenville County Schools District. After teaching middle school for five years, Storm moved to Riverside High School and instructed integrated mathematics classes for 2 years.

With a solid foundation of teaching experience formed, Storm accepted a position as an Aerospace Education Specialist for NASA's Aerospace Education Services Project. For 7 years Storm designed, implemented and facilitated various STEM programs to inspire teachers and students in STEM. As a "Space Mobiler", he used NASA missions to design and implement standards based activities that teachers could use to supplement their instruction. He also managed and developed curriculum support materials for the Exploring Space Through Algebra and Space Exploration AP Project

Storm returned to the classroom as the 8th grade STEM Magnet Mathematics Teacher at Marietta STEM Magnet Middle School where he was instrumental in developing the school's robotics team. This opportunity lead him to his current position as the Team Lead/Education Outreach Manager for the development of curriculum for the Robotics and Engineering Design Course at the Center for Education Integrating Science, Mathematics and Computing (CEISMC) at the Georgia Institute of Technology. His responsibilities include developing curriculum and providing professional development for teachers implementing robotics in their instruction through the NASA Electronic Professional Development Network.

\section{Mr. Jeffrey H Rosen, Georgia Institute of Technology \\ Dr. Marion Usselman, Georgia Institute of Technology}

Marion Usselman is a Principal Research Scientist and Associate Director for Federal Outreach and Research at the Georgia Institute of Technology's Center for Education Integrating Science, Mathematics and Computing (CEISMC). She earned her Ph.D. in Biophysics from the Johns Hopkins University and has been with CEISMC since 1996 developing and managing university-K-12 educational partnership programs. She currently leads up a team of educators and educational researchers who are exploring how to integrate science, mathematics and engineering within authentic school contexts and researching the nature of the resultant student learning.

\section{Dr. Jeremy A. Lingle, Georgia Tech}


Integrative STEM:

Design and Implementation of an $8^{\text {th }}$ grade Technology Curriculum

There is currently a national push towards moving STEM education away from the traditional silos of science, math and engineering and towards a more integrated model (Berland, 2013). This new model requires the design of new curriculum materials for all STEM curricular domains, including for Technology Education. The Robotics and Engineering Design Integrative STEM $8^{\text {th }}$ grade curriculum was developed by a South Eastern University, with support from a Race to the Top award, to provide a thoroughly tested set of instructional materials designed to help attract more students, particularly those previously underrepresented in STEM, into technical fields and careers. The skills taught are intended to enable students to pursue a life---long career in a STEM field. This paper will outline the development and implementation of the curriculum, relating it to the principles of Design Based Implementation Research (DBIR). Results of student pre and post achievement data from one of the courses will also be given.

\section{The Robotics and Engineering Design Integrative STEM $8^{\text {th }}$ grade Curriculum}

The Robotics and Engineering Design Course (REDC) provides students with engineering design experiences to develop systems thinking abilities while integrating mathematics and science concepts that support the decisions made in the design process. The goal of the course is for students to work through a design process and solve an authentic problem, applying mathematics and science skills that they should already have learned or are currently being taught. With background knowledge and appropriate research, students are expected to be able to design and manufacture a prototype based on data collected during scaffolded investigations.

The REDC is structured into four independent 9-week units, each of which can be taught as a self-standing Engineering and Technology exploratory elective. The units are 1) Biomechanics, 2) Electromagnetic Radiation (EMR), 3) Renewable Energy and 4) Analog to Digital Conversion. In each unit, students take the role of employees of an engineering company, responding to a "Request For Proposal "(RFP) by using LEGO ${ }^{\circledR}$ MINDSTORMS NXT robotics and 3-D prototyping to solve the relevant engineering challenge.

\section{Engineering Design Model}

The REDC units use a model of engineering design that correlates to the spiral model of product development by Sheppard, Macatangay, Colby and Sullivan (2009) shown below in Figure 1. 


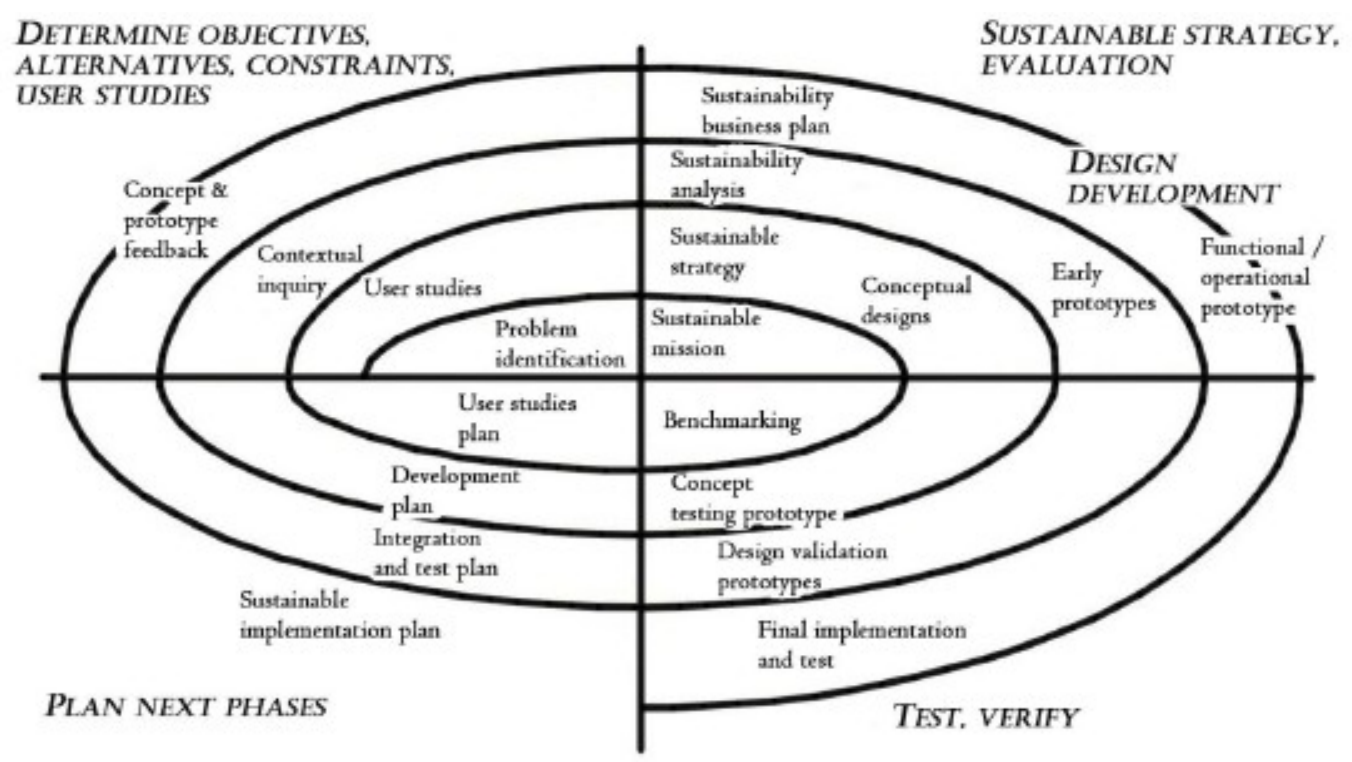

Figure 1.

(Grubbs, 2013)

The process begins with user studies and problem identification; continues through the development of a conceptual design, prototyping, and testing; and ultimately culminates in a sustainable implementation plan resulting in the creation of the marketable product designed to solve the problem. (Grubbs, 2013)

The iterative nature of the design process is apparent in this model. The iterations to the proposed solutions are prompted by the data collected and the analysis concluded from the data interpretation. It is evident from the model that there is an ability to shift back and forth through components to derive the desired solution. The real---world representation of the Engineering Design Process that is used in schools today to represent the spherical model can be shown in Figure 2 below.

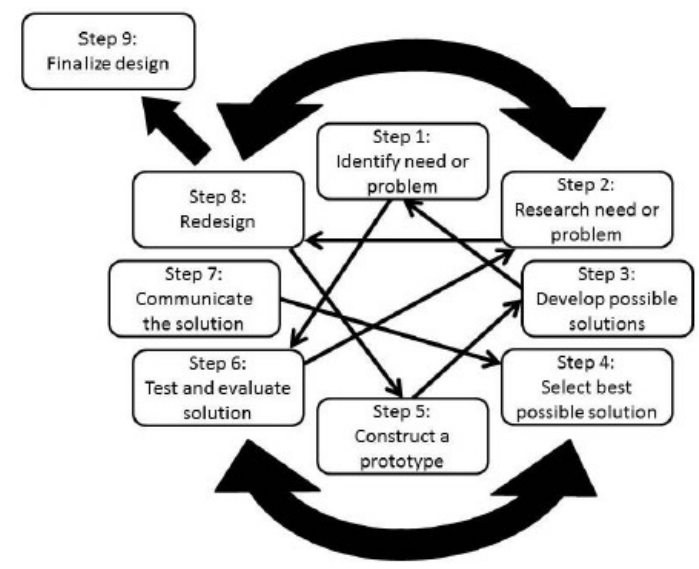

Figure 2.

(Grubbs, 2013) 
It should be noted that the representation of the model in this manner shows the ability of the student to shift to different stages of the design process. The shifting represents a real world context in how challenges are solved. Real world contexts are usually complex and at times unpredictable. Providing an environment that develops systems thinking gives a foundation for students to solve open ended engineering design problems and prepares them with skills needed to succeed in STEM environments (Grubbs, 2013).

\section{Curriculum Details}

The topics and contexts for each of the units were determined based on an informal survey of student interest and an analysis of the "richness" of the context to incorporate engineering principles with middle school---level mathematics and science concepts. The topics were also inspired by research done by the lead University in one of their physics laboratories, as well as by research done by the National Aeronautics and Space Administration (NASA). The basic flow of each of the courses is the same. This paper will highlight the Biomechanics course in detail.

Each design challenge is presented to the students as a Request for Proposal (RFP). The whole class represents the company responding to the RFP. The students are part of development groups inside of the company that propose solutions to the challenge to the whole company. The company decides on the appropriate solution using a design rubric. The RFP for the Biomechanics unit focuses on the locomotion of insects and how the understanding of the locomotion can be used to motivate innovation in the context of foot design. The unit is designed into six investigations. The investigations vary in length from three to eight days depending on the amount of material and the length of the school's class period.

Each unit begins with a mini unit that prepares the students for the basic structure of the unit. As an example, the Balloon Babble investigation gives an overview of the universal systems model and the engineering design process. Here students are introduced to the concept of a "Request for Proposal" (RFP). The RFP asks the students to determine which of three devices enables the students to inflate the greatest quantity of balloons in the least amount of time. Students experiment with the three devices to acclimate themselves to the system used to inflate the balloons, and each group is assigned one of the devices to test. The students then conduct experiments to determine the efficiency of their device. Students are instructed on record keeping and journaling using an engineering notebook. They make decisions based on the data collected and present their results to the company (i.e the whole class). The class decides which device best meets the criteria set forth in the RFP and formulates a response. The process is a short version of the rest of the unit and is used to prepare the students for the types of experiences they will have during the unit.

In Investigation 2 of the Biomechanics unit, for example, they begin with the essential question: What is locomotion and how do systems interact to allow locomotion? During the course of the unit students will redesign an existing robot to increase its stability and efficiency as it traverses varied terrains. Students in groups read the RFP and identify and record the criteria and constraints inside of their engineering notebooks. After a guided discussion about the criteria and constraints, the student groups begin familiarizing 
themselves with the system, conducting experiments to determine the optimal gait for the robot. Student use the calculation of velocity to describe the motion of the robot. In groups they engage in guided discussions to help them understand differences in locomotion, and specifically locomotion strategies using legs. Students gain a further understanding of locomotion by watching a video of bug locomotion, which serves to motivate discussion, thinking and innovation.

During Biomechanics Investigation 3, students gain a first-hand experiential understanding of locomotion and friction by conducting an experiment in which they walk and drag their feet over three different surfaces. This investigation introduces the science concepts of force, friction and energy. Then students extend their experimentation to the robotic model, traversing the three different terrains at different speeds. As students experiment with the robots they begin to focus their attention on the interaction of the robot's feet and the surface.

In Investigation 4 students begin gaining technological knowledge by learning how to use the LEGO NXT light sensors and data logging tools. When they have mastered the use of the data---logging feature, students use the tool to gather data related to the locomotion of their robot over different surfaces. Students record data taken using the light sensor to determine friction and moments of slippage. Students are able to calculate velocity and use this information to determine the efficiency of locomotion.

In Investigation 5, students begin to redesign their robot to increase its locomotive efficiency. With the focus solely on redesigning the foot of their robot, the students begin working with SolidWorks, a 3---D graphical tool. They are guided on how to use the tool to produce foot designs that they will then use to prototype the feet using 3---D Printing. During Investigation 6 the students make iterations to the prototype based on testing data. The students are encouraged to make at least three iterations.

With the last iteration done, students in their groups formulate a presentation in Investigation 7, explaining the reasons why their design meets the requirements of the RFP. After each student group presents their solution, the class decides on the solution that best meets the criteria. After the selection is made, each student drafts a formal response responding to the RFP requests and highlighting the design chosen.

The Electro Magnetic Radiation, Renewable Energy and Analog to Digital Conversion units all follow the same basic progression. The challenge is introduced using an RFP, students are introduced to the system involved, they perform activities to familiarize themselves with the system, and they then engage in research to aid in formulating their solution. Students design a prototype, and subsequently test and iteratively improve the design until they find a solution that best satisfies the criteria and constraints of the RFP. Student groups then present their solution to the company (whole class). The company selects one of the solutions based on the criteria and constraints of the RFP and formulates a response to the RFP. 


\section{Design Based Implementation Research}

The Integrative STEM learning environment lends itself to collaborations that reach across many stakeholders in education. The move from an official curriculum to an enacted and implemented curriculum is a challenging process that has to overcome obstacles of time, training and day---to---day instructional demands that are placed on teachers and schools (Brown, Brown \& Merrill, 2011). Overcoming these challenges includes coordinating the efforts of curriculum design specialists, content specialists, teachers and administrators to promote effectiveness of the curriculum. This collaborative effort is the underpinning of Design---Based Implementation Research (DBIR), which is used in the execution of this project (Penuel, Fishman, Cheng \& Sabelli, 2011). This approach focuses on the environment and practices that support the improvement and quality of teaching and learning in the CTAE classroom.

With the assumption that interventions face sustainability and scaling challenges, the use of DBIR as a model for design and implementation was chosen. DBIR is based on four key principles (Penuel, Fishman, Cheng \& Sabelli, 2011):

1. A focus on persistent problems of practice from multiple stakeholders' perspectives.

2. A commitment of iterative, collaborative design.

3. A concern with developing theory related to both classroom learning and implementation through systematic inquiry.

4. A concern with developing capacity for sustaining change in systems.

Examples will be given about how each of these principles was used to provide foundation and guide to the development of the REDC curriculum. Highlights from the design and implementation of the course development will be given to show the presence of the principles outlined. Issues related to the four principles and the execution of the model will accompany the highlights given.

\section{Focus from multiple stakeholders' perspectives}

At the onset of the design of the Robots and Engineering Design Course, the decision was made to form a team of school administrators, teachers, curriculum designers and practitioners to begin discussions laying out the challenges of instructing an integrative course of this nature. Inside of the definition of "integrative STEM" lies the call to incorporate two or more of the STEM subject areas in the instruction of a general STEM concept. This instruction could include the collaboration of more than just mathematics or science teachers (Becker \& Kyungsuk, 2011). The makeup of the team is not only found in the inclusion of mathematics, science and CTAE teachers, but also in the developers and researchers along with school administrative personnel.

The team held meetings to promote interest and identify the roles of each of the stakeholders. These meetings included school district personnel, school administrators, mathematics teachers, science teachers, CTAE teachers, and course designers. The REDC concept, based on learning through engineering design and integrated STEM, was introduced and the course overview given. The school personnel were generally intrigued 
with the curriculum being student centered and based on students acquiring systems thinking skills and not just getting an answer. This manner of learning is a deviation from the traditional manner of learning that is prevalent in most CTAE classes, with their use of prescribed modules in which everyone gets the same answer and outcome. More intriguing was that the course introduces students to tools, such as 3---D design and modeling, used by engineers and it develops skills that will prepare students for a career in STEM or provide them with experiences beneficial in any career path (Locke, 2009).

Instruction through engineering design calls for the change from strictly a hands-on experience to a learning experience that relies on trans disciplinary, analytical process that lead to optimal solutions (Hill, 2006). New instructional strategies such as this require the full backing and support of school administrators and district personnel. The core team agreed to the change and pledged to support the proposed new environment. Many changes were needed that included, but were not limited to, resource management, administrative scheduling, prioritizing of instructional time, and best practices of instructional strategies to be used. The participating schools began using new instructional technologies such as 3---D printers and in some cases LEGO NXT Mindstorms Robotics that require appropriate use and maintenance to insure reliability of performance and safety. Teachers required training and ongoing professional learning experiences to prepare them to use 3-D design, modeling and robotics in their instruction.

The space required for the course was an additional issue. At several of the participating schools, the school administration understood the need for providing a space that allowed for this manner of instruction and resources. At one school the teacher was assigned a classroom with an adjoining room to house the 3-D printer and robotics resources that was different than their regular classroom. Another school assigned two classrooms that were separated by a retractable partition. With the partition retracted, the room had twice the area for instruction. In the same school, the administrators supported the instruction practices and evolved their procedures for teacher observations around the new instructional practices. The changes would not have been made without the collaboration of the stakeholders.

\section{Commitment to Iterative, Collaborative Design}

Improving the instructional practices of the teachers involves including the teachers in the iterative design of the curriculum. The RED Course teachers were asked to participate in the development of the curriculum from the onset. The purpose of the inclusion was to emphasize their value and importance in the design process. The university-based design group communicated to the teachers that they were an integral part in this process and were heavily needed to produce a viable curriculum. From this inclusion, the teachers displayed a level of commitment that was needed for effective implementation.

Teachers were asked to make suggestions and adjustments during the training prior to the enactment of the curriculum. While participating in some of the activities, teachers gave input on which practices and activities they thought would work and which would not work, and why. Teachers' questions about STEM content were discussed and differences in how concepts were presented in different classes were resolved. In one such case, CTAE 
teachers were able to give input on how force tables were presented in engineering, which led to a stronger collaboration with the science teacher. After consulting with the science teachers at the respective schools, an adjustment was made to the manner in which force was discussed in the REDC classroom. This adjustment also helped solidified the instruction that was currently done in the science classroom regarding force and force diagrams.

\section{Concern with Developing Theory}

A key focus of the REDC project was to develop a theory describing the conditions necessary for successful implementation of 3-D design software and modeling in authentic middle school classrooms. This theory would include the conditions for scaling the use of this technology to a wide population of teachers. When introducing new technology, several questions have to be asked and answered. Does the related technology support the instruction of the skills needed for the instructional goals? Does the technology adhere to district's policies and procedures? Do teachers see the technology as part of the new vision for changing instructional practices? These questions relate to requirements of technology innovation (Blumenfeld, Fishman, Krajcik, Marx \& Soloway, 2000). The answers to these questions would inform the designers/researchers to refine the theory by analyzing teacher feedback and use of the technology.

During the Biomechanics unit teachers introduce students to the use of SolidWorks, a 3-D design software, to aid in the design of a foot for the robot. Initially, a half day training was given to the teachers with the assumption that they would have the appropriate skill to use the software in the classroom. This proved inadequate, as some teachers needed continual support to teach the investigation. This prompted a revision not only of how the investigation was written in the unit, but also of the theory of thought regarding the training using the 3---D software. The software training changed from being a half day session to occurring every day during the weeklong professional development experience.

\section{Developing Capacity for Sustaining Change}

The issue of developing a capacity for sustainability is a matter of concern in the DBIR model. Several factors have been identified to promote sustainability of the course at individual schools after project funding ends, and to increase the likelihood that the curriculum can be successful scaled up. Not surprisingly, teacher professional development is the most critical issue, as design-based and inquiry-oriented teaching and learning presents a substantial change for many teachers, and courses that incorporate new technologies can be daunting to them. It was determined from feedback from all of the teachers that the initial professional development offered for the course lacked sufficient detail, and that the designers of the professional development needed to focus on very specific instructional strategies for each of the investigations. Appropriate professional development activities that truly immersed them in the REDC's design-focused environment gave the teachers a greater understanding of what to expect from their students and helped them align their instruction to meet the learning objectives mandated by state standards. Professional development also had to adequately teach the teachers how to use the new technologies integral to REDC. In response to feedback received from the teachers, sessions were designed to allow the teachers to train on the use of the 3-D modeling software daily during the summer institute, with a full day reserved for training on the 3-D printer. These experiences gave the teachers confidence on their ability to incorporate these tools in their instruction 


\section{Early Indications of Student Learning}

As noted previously, the goal of the RED course is for students to work through a design process and solve an authentic problem by applying mathematics and science skills that they should already have learned, or are currently being taught. A short pretest and post test was administered to students participating during the first quarter of academic year 2013-2014 for the purpose of capturing changes in student knowledge of the relevant math and science concepts. A total of 105 students participating at four school sites are included in this analysis. Approximately one-third of students were White at $34 \%$, a little less than a quarter of the students were Latino/a at 23\%, a fifth of the students were African American at $21 \%, 12 \%$ were multiracial, $6 \%$ were Asian, and $4 \%$ selected "other" ethnicity. Just over half of the students were female at $54 \%$.

Test item development included consideration of the specific content areas that were addressed through the REDC Units. Although publicly---available, released items were reviewed in the creation of the assessment, the items included in the assessment were created by the course development team and evaluation team and reviewed by a participating teacher. Items were tested with students during Quarter 4 of the 20122013 academic year to determine the difficulty of items.

All teachers implemented the Biomechanics Unit during the first quarter. The content standards that are addressed by this unit and that were tested through the pretest and post test were:

1. Science - Students will investigate the relationship between force, mass, and motion of objects.

a. Determine the relationship between velocity and acceleration.

b. Demonstrate the effect of balanced and unbalanced forces on an object in terms of gravity, inertia, and friction.

2. Math

a. Graph proportional relationships, interpreting the unit rate as the slope of the graph. Compare two different proportional relationships represented in different ways.

b. Describe qualitatively the functional relationship between two quantities by analyzing a graph (e.g., where the function is increasing or decreasing, linear or nonlinear). Sketch a graph that exhibits the qualitative features of a function that has been described verbally.

The table below presents the percent of students who answered items correctly on the pretest and posttest and the percent change from pretest to posttest. 
Table 1. Percentage (\%) of Students Responding Correctly per School ( $\mathrm{n}=105)$

\begin{tabular}{|c|c|c|c|c|c|c|c|c|c|c|c|c|}
\hline \multirow[t]{2}{*}{ School } & \multicolumn{3}{|c|}{ Overall } & \multicolumn{3}{|c|}{$\begin{array}{c}\text { Velocity/Graphing } \\
\text { [3 items] }\end{array}$} & \multicolumn{3}{|c|}{$\begin{array}{c}\text { Force } \\
{[2 \text { items }}\end{array}$} & \multicolumn{3}{|c|}{$\begin{array}{c}\text { Proportional } \\
\text { Relationships } \\
\text { [2 items] }\end{array}$} \\
\hline & & & $\Delta$ & Pre & Post & $\Delta$ & Pre & Post & $\Delta$ & Pre & Post & $\Delta$ \\
\hline $1(n=13)$ & 23 & 43 & 20 & 33 & 62 & 28 & 15 & 31 & 15 & 15 & 27 & 12 \\
\hline $2(\mathrm{n}=32)$ & 32 & 44 & 12 & 38 & 60 & 23 & 20 & 22 & 2 & 34 & 41 & 6 \\
\hline $3(n=33)$ & 45 & 50 & 5 & 54 & 54 & 0 & 27 & 30 & 3 & 48 & 64 & 15 \\
\hline $4(n=27)$ & 45 & 54 & 9 & 53 & 67 & 14 & 37 & 31 & ---6 & 41 & 57 & 17 \\
\hline Overall & 38 & 48 & 10 & 46 & 60 & 14 & 26 & 28 & 2 & 38 & 50 & 12 \\
\hline
\end{tabular}

Note: Velocity/Graphing = Science Standard A and Math Standards A and B

Force $=$ Science Standard B

Proportional Relationships $=$ Math Standards A and B

The seven items of the test that captured standards that were addressed by the Biomechanics Unit showed an increase between the pretest and posttest of $10 \%$, which was a significant increase ${ }^{1}$. Considering the change in percent correct among those items addressing specific content areas, those items related to determining the relationship between velocity and acceleration using graphs showed the greatest increase from pretest to posttest of $14 \%$. These items integrated both the math and science concepts related to Science standards S8P3a and touched on all math concepts, requiring interpretation of acceleration of robots plotted on graphs. Two items focused specifically on the science concepts related to forces and friction (Science standard b). The change from pretest to posttest was very small on these items, with an average $2 \%$ increase. In one school, the percent of students who answered this question correctly decreased. Two items of the assessment focused specifically upon the mathematics skills related to interpreting relationships using graphs, and included no science concepts, the results of which are presented in the final column of the preceding table. On these items, students showed an increase of $12 \%$ from pretest to posttest.

These results provide indication of an increase in the students' ability to interpret and use information presented in graphs. The activities of the Biomechanics Unit include utilization and interpretation of graphs of velocity and acceleration in order for students to optimize the performance of their robots. Likewise, the mathematics test items are also related to interpreting slope. These skills are reinforced through participation in this unit. Exposure to force diagrams gives the students understanding of friction and slippage. This understanding narrows their focus to the interaction of the robot's foot and the surface. | The data collected informs the student's decision on the design for an optimal foot.

\footnotetext{
${ }^{1}$ Paired samples t---test of number correct on pretest and posttest: $t=4.2, \mathrm{df}=104, \mathrm{p}<.01$
} 


\section{Conclusion}

The Robotics and Engineering Design Course has been developed and implemented using the principles of Design Based Implementation Research. The course has a foundation in engineering design while integrating relevant mathematics and science concepts, and has been developed and implemented by teams of stakeholders such as school administrators, teachers and curriculum designers and practitioners. Because they actively participate in the iterative development of the curriculum, teachers can take ownership and promote changes determined from problems of practice.

Early data collected through pre and post content tests show that the REDC helps students master related STEM skills, particularly math skills associated with graphing and the analysis of slope. 


\section{References}

Becker, K., \& Kyungsuk, P. (2011). Effects of integrative approaches among science, technology, engineering, and mathematics (stem) subjects on students' learning: A preliminary meta-analysis. Journal of STEM Education: Innovations \& Research, 12(5/6), 2337.

Berland, L. (2013). Designing for stem integration. Journal of Pre-College Engineering Education Research,3(1), 22-31.

Blumenfeld, P., Fishman, B., Krajcik, J., Marx, R., \& Soloway, E. (2000). Creating usable innovations in systemic reform: Scaling up technology-embedded project-based science in urban schools. Educational Psychologist., 35(3), 149-164.

Brown, J., Brown, R., \& Merrill, C. (2011). Science and technology educators' enacted curriculum: Areas of possible collaboration for an integrative stem approach in public schools

. Technology \& Engineering Teacher, 71(4), 30-34.

Grubbs, M. (2013). Robotics intrigue middle school students and build stem skills. Technology and Engineering Teacher, 72(6), 12-16.

Hill, R. (2006). New perspectives: Technology teacher education and engineering design. Journal of Industrial Teacher Education, , 43(3), 45-63.

Householder, D., \& Hailey, C. National Center for Engineering and Technology Education, (2012).Incorporating engineering design challenges into stem courses. National Center for Engineering and Technology Education.

Locke, E. (2009). Proposed model for a streamlined, cohesive, and optimized k-12 stem curriculum with a focus on engineering. Journal of Technology Studies, 35(2), 23-35.

Penuel, W., Fishman, B., Cheng, B. H., \& Sabelli, N. (2011). Organizing research and development at the intersection of learning, implementation, and design.Educational Researcher, , 40(7), 331-337. 